\title{
Research on the Application of Hydraulic Lifting Technology on Complex Hyperboloid-shaped Steel Space Truss
}

\author{
Pan Xueqiang, Tao Wei, Xu Yonglei, Li Yuandi, Xing Gang,Li Zhen \\ China Construction Steel Structure Co. Ltd. Shen Zhen, 518040 \\ 345184963@qq.com
}

\begin{abstract}
Keywords: hyperboloid,steel space truss, hydraulic lifting,numerical simulation,stress ratio Abstract:In this paper, the sectionalized and blocked hydraulic lifting technology is proposed directing at the complex hyperboloid-shaped weld ball-node grid structure of the newly-built airport terminal in Xinjiang Korla Airport. Firstly, Numerical simulation is made to the sectionalized hydraulic lifting process, then the stress ratios of the synchronous Lifting condition and the non-synchronous Lifting condition are analyzed. Finally, section increment is made to the circular tube bar of which the stress ratio has exceeded the value of 0.85 to guarantee the security of the construction and structure of the complex hyperboloid-shaped steel space truss.Introduction
\end{abstract}

\section{Project overview}

The overall construction area of the newly-built terminal of Xinjiang Korla Airport reconstruction and extension project is $25925.14 \mathrm{~m}^{2}$, the structure of the lower part is reinforced concrete frame structure, the structure of the roof of the upper part is the welding hollow sphere node quadrangular pyramid wire frame, the size of the grid cell is about $3 \mathrm{~m} \times 3 \mathrm{~m}$. The steel truss of the roof is hyperboloid-shaped, and the shape is unique. The plane projection size is $99 \mathrm{~m} \times 199 \mathrm{~m}$, and the maximum span is $36 \mathrm{~m}$, the elevation of the highest point is $+25.5 \mathrm{~m}$, the elevation of the lowest point is $+12.12 \mathrm{~m}$, the thickness of the frame is $2 \mathrm{~m} \sim 2.5 \mathrm{~m}$, and the total weight is 1200 tons. Axis A, Axis D, Axis $\mathrm{G}$ are supported by steel pipe columns. The steel pipe column that support Axis $\mathrm{G}$ are umbrella-shaped. There are 24 ( $6 \times 4$ ) supporting steel column, with 11 diagonal side bracing columns in Axis $A$ and Axis $G$ respectively, with both sides of axis $2 \sim$ axis 4 and axis $16 \sim a x i s ~ 18$ setting reinforced concrete column, and the concrete column top support elevation is $11.72 \mathrm{~m} \sim 13.11 \mathrm{~m}$. The supporting of the steel structure net frame is on the support and concrete column, and the steel structure of the main structure is shown in Figure 1.

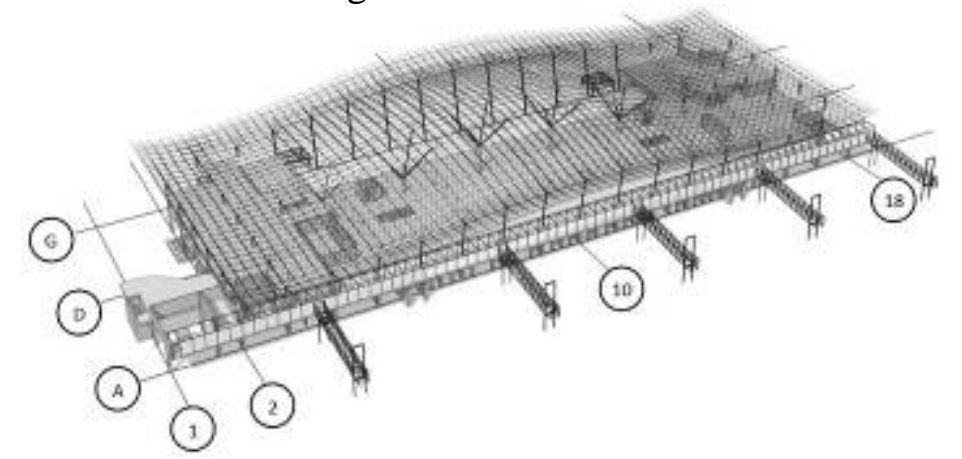

Figure 1 General view of new-built terminal steel structure

\section{Lifting construction technology space truss}

\section{Lifting construction}

With a higher installation height and large quantity of structural rods of Roof steel grid, the regular block lifting and unloading program would cost a great amount of supporting bed-jigs, Which will not only cause a large amount of high-altitude assembly and welding workload,but also a poor technical and economic performance index, and exist a large quality, security risks. The hydraulic 
synchronization Lifting system control the synchronization point through the computer to enhance the process with smooth structure balance during the Lifting, the synchronous control is of high ${ }^{[1-4]}$ accuracy, which is safe and reliable, It could be reliable locked in any position, effectively improve the installation precision ${ }^{[5]}$ of the lifting structure with good feasibility and economy ${ }^{[6]}$. According to the characteristics of the roof structure, the grid partition will be assembled into the block unit, and lifted to the design elevation by use of "hydraulic synchronous construction technology", and then install of the post-installed parts, which will be greatly reduced the high-altitude workload and difficulty of construction.

According to the characteristics and difficulties of this project, steel gird construction in situ assembly, partition hydraulic lifting method shall be adopted. Figure 2 is the view of truss partition and lifting process. The construction process will including the following phases:1) steel gird Lifting and unloading of section A; 2)connecting with section B2 after Lifting of section B1, then lift and unload them as a whole; 3) lift and unload for section D; 4)connecting with section C2 after Lifting of section $\mathrm{C} 1$,then lift and unload as a whole.

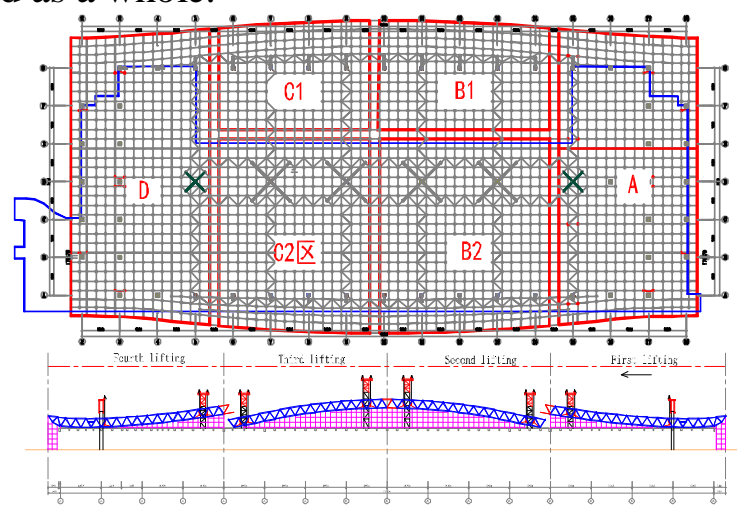

Figure 2 View of truss partition and lifting process

\section{Setting the Lifting point}

According to the characteristics of the project grid, set the temporary lifting point, to enhance the lifting point of the specific location determined by the three-dimensional loft, as shown in Figure 3.take the welding ball joints as Lifting points, The middle of the welding ball is provided with steel pipe, the bottom stiffening plate and the bottom plate are used to connect with the special bottom anchor, the temporary bar is made of $\varphi 159 \times 10$ steel pipe, the temporary lifting welding ball adopts WS450 *22, the temporary rod and the temporary ball material are Q345B, The field installation effect shown in Figure 4.
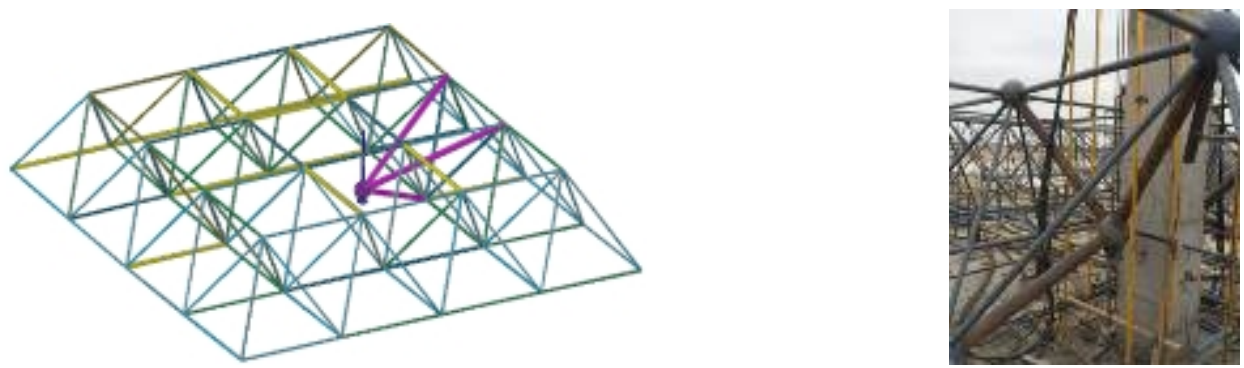

Figure 3 View of elevating hanging points Figure 4 Drawing of site installation

\section{Lifting frame design}

According to the steel structure of this project, two different lifting points are set up. We adopt the structural concrete column as the lifting point at the axis 2,axis 3,axis 17 and axis 18 , standardized lattice braced frames were fixed up at the other lifting points. Without any impact to the Lifting,we designed Lifting frame according to the two different lifting points, with no collision to the reserved bars and easy unloading. The designs are shown in Figure 5. 


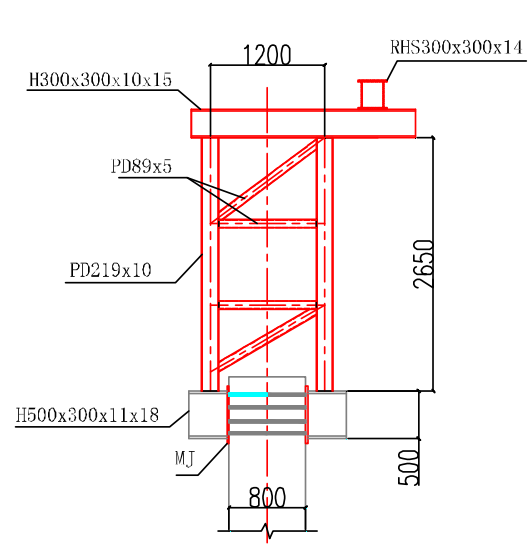

( a ) Lifting frame at concrete column

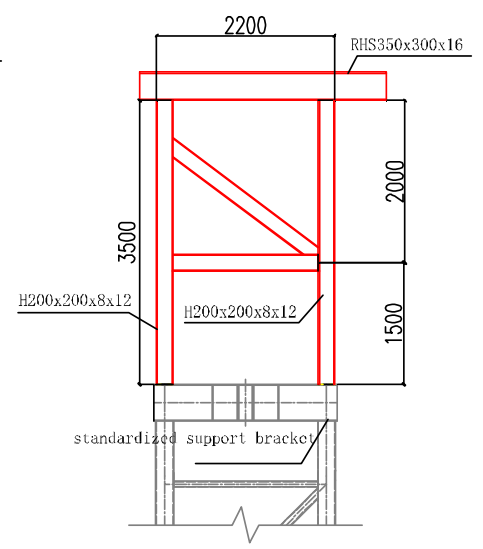

( b ) Lifting frame at support bracket

Figure 5 Schematic design of lifting frame

As shown in Figure 6 and Figure 7, numerical simulation software is used to analyze the most unfavorable conditions of two kinds of Lifting frame. As a result, the maximum stress ratio of the lifting frame at concrete column is 0.563 , and the maximum stress ratio of the lifting frame at support bracket is 0.83 . The two maximum stress ratios are less than 1 , which meets the requirements of the specification.

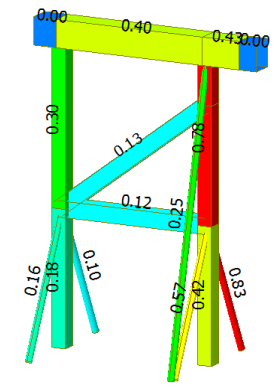

Figure 6 View of stress ratio of concrete column lifting frame Figure 7 View of stress distribution in temp support

\section{Lifting equipment layout}

According to the numerical simulation, based on the lifting plan and improving working condition, We set up 22 TLJ - 600 through core type hydraulic lifter, recycling for 2 times, and 2 TL - HPS60 type hydraulic pump systems, using for 4 cycles. A total of 44 ascending points, lifting points and Lifting frame layout are shown in figure 8. Each lifter have 3 high strength prestressed steel strands, with tensile strength of $1860 \mathrm{Mpa}$ and diameter of $17.80 \mathrm{~mm}$. Through numerical simulation, the maximum lifting force of the lifting point is $377 \mathrm{KN}$, with the maximum lifting force of the hydraulic hoist

$$
\mathrm{W}_{1}=\mathrm{n} * \mathrm{PS}=3 * 1860 * 3.14 *(0.0178 / 2) 2=1387.8 \mathrm{KN}>377 \mathrm{KN},
$$

In equation (1), $W_{1}$ is the lifting force of a single lifting point, $n$ is the number of steel strand (root), $P$ is the tensile strength of the steel strand, and $\mathrm{S}$ is the cross sectional area of the steel strand (m2). It can be seen from equation (1) that the single lifting point meets the load requirements.

The total lifting force of 44 elevating points is

$$
\mathrm{W}_{2}=\mathrm{n} * \mathrm{~W}_{1}=44 * 1387.8=61063.2 \mathrm{KN}>12000 \mathrm{KN} \text {, }
$$

In equation (2), $\mathrm{W}_{2}$ is the total lifting force, $\mathrm{n}$ is the number of hoist (table), and $\mathrm{W}_{1}$ is the lifting force of single lifting point. According to formula (2), it can be seen that the enhanced capability meets the requirement of lifting. 


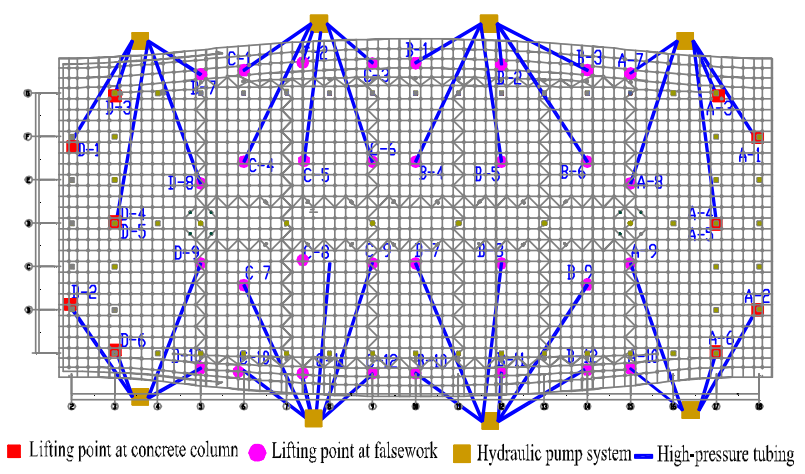

Figure 8 diagram of Lifting frame distribution

\section{Lifting condition analysis}

In the process of steel truss lifting, there is a certain deviation which comes from the Hang-point desynchrony. Therefore, it is necessary to consider the impact on structure ${ }^{[6]}$. In the actual process of integral lifting, the pressure sensor and displacement sensor on the lifter can feedback the real-time information to the computer ${ }^{[5,7]}$, therefore, the synchronicity of the lifting point can be adjusted by controlling the pressure and displacement. According to the standard ${ }^{[8]}$, the difference should be L / $250=18000 / 250=72 \mathrm{~mm}$. When the stress ratio of the bar is greater than 0.85 in the synchronous lifting condition, the bar should be replaced. And when the stress ratio is greater than 0.85 the bar should be replaced ${ }^{[9]}$. Table 1 shows the influence of the value which calculated by the displacement deviation without synchronization, on structural internal force. It can be seen from the table that the number of structural rod replacement needs to be increased with the increase of the deviation of displacement deviation.

Table 1 Number of rod replacement under out-sync lifting check

\begin{tabular}{c|c|c}
\hline $\begin{array}{c}\text { Displacement } \\
\text { deviation }(\mathrm{mm})\end{array}$ & $\begin{array}{c}\text { Number of structural rod } \\
\text { replacement }\end{array}$ & $\begin{array}{c}\text { Percentage of replace structural bars } \\
\text { in A area ( \% ) }\end{array}$ \\
\hline 30 & 96 & 2.60 \\
\hline 50 & 177 & 4.78 \\
\hline 70 & 289 & 7.81 \\
\hline
\end{tabular}

Table 2 shows the anti-force value of lifting points in A zone with simultaneous lifting condition. Figure 9 shows the anti-force value of the lifting point of the lifting point of A zone simultaneously. It can be seen from the figure that the anti-force value of the lifting points fluctuates greatly, and the maximum reaction value is $152 \mathrm{KN}$ with the minimum anti-force value. According to the research of Zhou limin's team ${ }^{[1]}$ research, it is difficult to control the stress of the lifting point accurately with the displacement synchronization control, and it is difficult to accurately control the stress of the lifting point. The smaller the displacement deviation, the closer to the simultaneous improvement. Simulation calculation, therefore, to improve point not synchronizing lifting force value is less than that point synchronous reaction value increased by $25 \%$, while the lifting point out of sync displacement values are not more than $50 \mathrm{~mm}$, for space truss model is out of sync check ascension.

Table 2 Reaction value of synchronous lifting check in A area

\begin{tabular}{c|c|c|c|c|c}
\hline Lifting point & A-1 & A-2 & A-3 & A-4 & A-5 \\
\hline Anti-force value (KN) & 125 & 122 & 260 & 114 & 119 \\
\hline Lifting point & A-6 & A-7 & A-8 & A-9 & A-10 \\
\hline Anti-force value (KN) & 195 & 130 & 187 & 187 & 108 \\
\hline
\end{tabular}




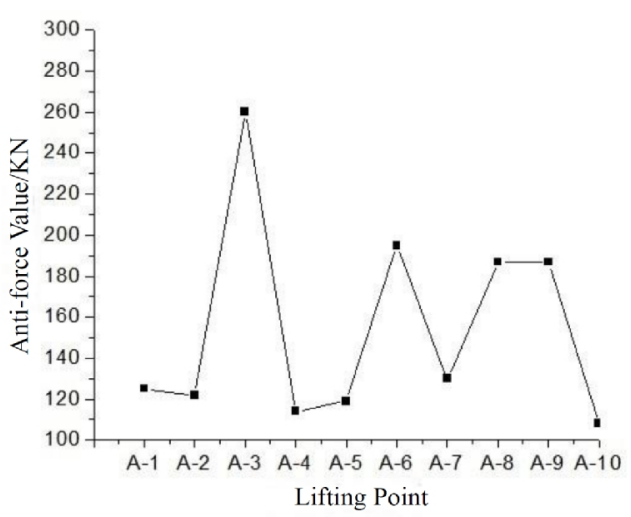

Figure 9 Line chart with reaction value of hanging point under synchronous lifting check in A area

Taking the steel truss of A zone as an example, the checking of the condition of the unsynchronized lifting condition is carried out. Under the condition of unsynchronized lifting, the internal force of the lattice structure will be redistributed, and the stress of the rod may exceed the allowable value. Figure 10 shows the stress ratio diagram in the condition of the non-synchronous lifting of A region. Through the model calculation, it can be concluded that in the case of non-synchronous lifting, the stress of 115 rods in A zone exceeds the allowable value, and the cross-section of the section should be increased. Figure 11 shows the stress ratio of the net frame after the replacement of the bar in A region, and it can be seen that the maximum stress ratio of the frame bar is 0.82 in the unsynchronized lifting condition after the replacement of the bar, meeting the requirements of the lifting. In the same way, the checking of the operating conditions of $\mathrm{B}, \mathrm{C}$ and $\mathrm{D}$ is carried out, and the results are shown in table 3 below.

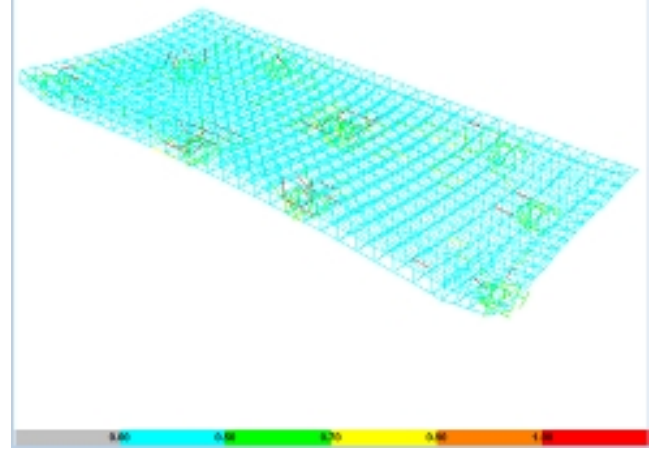

Figure 10 View of stress ratio with different motion conditions Figure 11 View of stress ratio after rod replacement

Table 3 Out-sync lifting check of A,B,C,D area

\begin{tabular}{c|c|c}
\hline Area & $\begin{array}{c}\text { Number of structural rod } \\
\text { replacement }\end{array}$ & $\begin{array}{c}\text { The maximum stress ratio of rod } \\
\text { replacement }\end{array}$ \\
\hline A & 177 & 0.82 \\
\hline B & 219 & 0.83 \\
C & 139 & 0.83 \\
\hline D & 112 & 0.84 \\
\hline
\end{tabular}

\section{Measurement of deflection of steel frame}

According to the requirements of standard GB 50205-2001, the deflection value should be measured after the installation of steel structure truss, and the deflection value should not exceed L / 250 , and $\mathrm{L}$ is the network frame structure span ${ }^{[10]}$. Check quantity: span $24 \mathrm{~m}$ and the following steel grid structure to measure the center of the lower chord 1 point; The steel mesh frame with span of $24 \mathrm{~m}$ is measured by the center 1 point of the lower chord and 4 equal points of the lower chord span. Use the full station to carry out the test. Since the maximum span of this project is $36 \mathrm{~m}$, it is greater than 
$24 \mathrm{~m}$, so 5 points are selected from the A, B, C and D area for the measurement. 4 points of span and the span of the second string. Table 4 is the maximum value for $\mathrm{A}, \mathrm{B}, \mathrm{C}$ and $\mathrm{D}$ partitions. It can be seen from the table that after the actual measurement, the lower scratch value meets the requirements of gb50205-2001, so the steel truss is qualified to scratch.

Table 4 Measured value of deflection

\begin{tabular}{c|c|c|c|c}
\hline $\begin{array}{c}\text { Serial } \\
\text { number }\end{array}$ & $\begin{array}{c}\text { Measuring } \\
\text { point }\end{array}$ & $\begin{array}{c}\text { Design elevation } \\
(\mathrm{mm})\end{array}$ & $\begin{array}{c}\text { Measured elevation } \\
(\mathrm{mm})\end{array}$ & $\begin{array}{c}\text { Down warping } \\
\text { value }(\mathrm{mm})\end{array}$ \\
\hline 1 & $\mathrm{a} 2$ & 13334 & 13312 & -22 \\
\hline 2 & $\mathrm{~b} 4$ & 22664 & 22645 & -19 \\
\hline 3 & $\mathrm{c} 3$ & 18119 & 18092 & -27 \\
\hline 4 & $\mathrm{~d} 3$ & 13685 & 13659 & -26 \\
\hline
\end{tabular}

\section{Conclusion}

To sum up, apply the hydraulic lifting method in construction of the complex double curved surface steel truss, is advanced rational and security which will be popularized. The construction of Complex Hyperboloid-shaped Steel Space Truss in Xinjiang Korla airport new terminal hyperboloid was successfully completed by applying hydraulic lifting. through the numerical simulation and analysis of stress ratio of the rods in cross section, to ensure the network frame construction quality and safety, and confirmed the feasibility of the construction technology of the ascension, reduces the overhead construction and installation construction difficulty.

\section{Reference}

[1] Zhou Limin,Fu Ran,Zhang Hongbo,etc.Synchronization of Heavy Load Hydraulic Lifting System. Chinese Hydraulics \& Pneumatics, Vol 12(2012) p.82-84.

[2] Lu Ning.Technology and Technical Safety Measurea for Hydraulic Lifting of Integral Long-Span Steel Grid-Frame.Building Construction, Vol 33 ( 2011) p. 194-209 .

[3] Zhang Tongbo,Fu Changchun,Wang Hui.Steel Structure Construction Technology of Qingdao Sports Center Swimming Diving Hall. Construction Technology, Vol 38(2009) p. 48-53.

[4] Li Wenming,Zhang Hongliang,Zhang Fan,etc.Integral Hydraulic Synchronous Lifting Technology of 120t Steel Truss Roof. Construction Technology, Vol 12(2012) p. 375-379.

[5] Li Hailiang.Research on hydraulic successive lifting robot based on XC164CS.ShangHai: Tongji University, (2009) p.1-78.

[6] Dong Kang,Chen Haizhou,Wang Yuling,etc. Flexible Lifting Technique for Super Large Solder Ball Space Truss Roof. Construction Technology, Vol 42(2013) p. 17-61.

[7] DG/TJ08-2056-2009.Technical Specification for Integral Lifting of Heavy Structure (equipment)

[8] Zhang Jigang,Zhang Tongbo. Simulation Analysis and Construction $M$ onitoring ot Grid Structure for Swimming and Diving Hall in Qingdao Sports Center. Construction Technology, Vol 38(2009) p. 30-32.

[9] Chen Dongdong,Yao Gang,Yuan Xudong,etc. Integral LiftingTechnology of Boeing Hangar Roof at Pudong Airport. Journal of Chongqing Jiaotong University (Natural Science), Vol 29(2010) p. 650-653.

[10] GB50205-2001.Code for Acceptance of Construction Quality of Steel Structure Engineering. 